\title{
Assessing the Level of Laboratory Resources for Teaching and Learning of Chemistry at Advanced Level in Lesotho Secondary Schools
}

\author{
Mosotho J. George \\ Department of Chemistry and Chemical Technology, National University of Lesotho, P.O. Roma 180, Lesotho.
}

Received 1 November 2016, revised 24 July 2017, accepted 26 July 2017.

\begin{abstract}
Despite the importance of science education in the establishment, maintenance and support of a knowledge economy, the ensuing economic challenges facing Lesotho deprive schools and pupils of some important resources, namely laboratories and the associated accessories required for quality delivery of teaching. This manuscript reports on the results of a survey on the resources available for teaching chemistry at secondary schools in preparation for the introduction of an advanced level (A level) curriculum in Lesotho schools. The survey was administered to first-year students registered at the National University of Lesotho for different science-based degrees. The findings from the survey showed that about $90 \%$ of the schools had physical laboratories although on average $70 \%$ of the students reported not having performed more than five experiments over the last year of the secondary school education. Only two schools reported having performed between 15 and 20 experiments of the more than 20 prescribed in the syllabus. The reasons cited ranged from poor facilities, for example poor or no benchtops, no or unusable fumehoods, lack of general apparatus and glassware, a poor range of suitable chemicals, to interestingly, the experiments not even being scheduled in the timetables. The study concludes that the schools in Lesotho are not ready to offer A level chemistry and suggests some recommendations that could be considered should the introduction of A-level be implemented in the near future.
\end{abstract}

KEYWORDS

Chemistry education, laboratory experiments, A-level, secondary schools, Lesotho.

\section{Introduction}

Mathematics and science education is one of the most strategic areas of basic education that requires a lot of attention if any country hopes to achieve sustainable development goals. This is because these subjects are recognized as 'enabling' subjects that are central to most careers in technology, health and engineering, ${ }^{1}$ as well as finance and economics ${ }^{2}$ which have the potential to improve countries' economic profile. ${ }^{3,4}$ It is reported that without science subjects, students face significant consequences for their educational and career choices on leaving school. ${ }^{5}$ However, these subjects require significantly more investment than the other subjects since laboratory facilities must be provided over and above the normal teaching classrooms, chalk and textbooks. A 2011 UNESCO report on Lesotho showed that there was a shortage of maths and science teachers entering the system while those in the languages were in over-supply. ${ }^{6}$ There is a need to improve the enrolment and investment in the Least Developed countries where there is reportedly generally poorer appreciation of science. ${ }^{7,8}$

Lesotho, classified as a developing country, is a wholly landlocked country inside South Africa with the reported national poverty head count rate of $57.1 \%$ in $2010 / 11,{ }^{9}$ while the Central Bank of Lesotho in 2009 reported that close to $68 \%$ of the population lived below the national poverty line. ${ }^{10}$ This is exacerbated by the unemployment rate that has been declared a national

* To whom correspondence should be addressed. E-mail: jm.george@nul.Is / maluti2005@gmail.com crisis. ${ }^{11}$ Basic education in Lesotho spans twelve years, consisting of seven-years primary level, three-years lower secondary (Junior Certificate) and a two-year upper secondary sometimes called high school level with a Cambridge Overseas School Certificate (COSC) qualification which was replaced with the Lesotho General Certificate of Education (LGCSE) in 2013. The first candidates for the latter qualification started their higher education in the 2015/16 academic year. The improvement in the structure of the LGCSE over the COSC is that the candidates are mandated to take at least one natural science subject although this does not necessarily mean the students have to pass these subjects.

Access to basic education has increased substantially over the last decade since the adoption of a free primary education policy over a decade ago in Lesotho. ${ }^{12}$ However, there is still a challenge of getting all children into the classrooms since some children are forced into child labour. For example, boys whose parents are unemployed or who act as heads of orphaned families are hired out as herd-boys; ${ }^{13}$ while girls under the same predicament are coerced into being either domestic or sex workers. ${ }^{14,15}$ Allocation of the annual budget to education in Lesotho is reported to be the highest in Africa at $16 \%$ of the total annual national budget ${ }^{16}$ spread between higher education $(36.4 \%)$ secondary $(36 \%)$ primary $(20.5 \%)$ and early childhood care $(1 \%)$. Interestingly, a recent study revealed that an average book price per child in Lesotho is second highest at almost US\$150.00 after Uganda for the eleven countries studied namely Botswana, Cameroon, 
Ivory Coast, Ghana, Kenya, Malawi, Nigeria, Tanzania and Togo with Tanzania the cheapest at about US\$25.00. ${ }^{17}$

Financing of secondary education on the other hand, is still shouldered by private citizens, thus it places a huge burden on the already poverty struck families plagued further by the unemployment crisis. ${ }^{11}$ This is despite the public schools category receiving financial support in the form of salaries of the teachers from government. However, this payment is said to be plagued by some systemic inefficiencies such as delayed payment for the newly employed teacher where they can go several months without their first payment. ${ }^{18}$ These schools are also said to be eligible for government grants as well although it is reported that this subvention is intermittent; it is given in variable amounts in some years and not in others. The private schools on the other hand do not receive any financial support from government and their number is quite low compared to the public category. As expected, the fees for these schools are significantly higher than the public counterparts and they are primarily accessible for the middle class citizens who can afford the higher fees. However, both private and public schools are required by law to be registered and certified to meet the minimum requirements of the secondary education by the Ministry of Education and Training.

In 2012, the Government of Lesotho introduced a school fee regulation where the government prescribed the cap on the fees for the public schools namely those that are owned by government, churches or communities, $92 \%$ of which are reportedly owned by churches. ${ }^{19}$ However, this regulation of fees has caused a lot of debate in society, prompting the Lesotho Parliament to embark on a study to investigate the effects of the regulated fees. ${ }^{20}$ Notwithstanding the regulation, some studies report that there is lack of financial and budgeting capacity in schools leading to principals dominating other teachers and even school boards sometimes to the detriment of the functionality and sustainability of the schools. ${ }^{21}$

The multi-pronged propriety of the schools is susceptible to funding challenges since the churches are not profit-making organizations and rely on the good will of the congregants for income, hence their resources are almost always limited. Therefore it is justifiable to predict that such schools would be less well-resourced than the government and private schools. Due to poor funding resources, infrastructure development is poor, especially for the teaching of maths and science subjects as has been stated earlier. The level of maths and science resources spans a wide spectrum, from those schools with no physical laboratories to those that have a beautiful laboratory with benches but no apparatus and consumables. In situations like these chemistry is the worst hit since most of the chemistry experiments require use of chemicals which are discarded at the end of the experiment and are not recyclable. This situation deprives the students of the benefits of performing experiment ${ }^{22}$ leading to difficulty in understanding the sometimes abstract theory, which results in students losing interest and eventually leaving the science subjects. ${ }^{6}$ Studies revealed that lack of physical facilities like laboratories and libraries contribute negatively to the performance in natural sciences at secondary schools. ${ }^{23}$ However, Lekhetho reported that only a small proportion of stakeholders (students $-4 \%$, teachers $-4 \%$, principals $17 \%$ and board members $-24 \%$ ) cited the lack of physical facilities as a factor contributing to poor performance at secondary school level. ${ }^{24}$ The need for experiments in learning and teaching of science, especially chemistry, should be emphasized with the lack of laboratories being likened to painting without colours and canvas or learning how to ride a bicycle by reading its operating manual..$^{25}$
The use of virtual laboratories, video demonstrations, simulations and animations as an alternative and complementary resource has found considerable attention in the Developed World. ${ }^{26}$ These resources eliminate the risk of exposure to hazardous materials such as acid fumes, explosive reactions as well as saving time taken for preparations, carrying out the experiment and subsequent disposal of waste. ${ }^{27}$ These resources can also enhance teaching in that it is easier to pause and replay as necessary while stimulating the learners' interest as well as being able to correlate macroscopic, sub-microscopic and symbolic levels of scientific presentation. ${ }^{28}$ There are a number of web-based resources for teaching and experimental demonstrations for sciences such as Virtlab, The Chemistry Collective, Royal Society of Chemistry Demonstration Videos, to mention but a few. ${ }^{27}$ The challenge in Lesotho for employing these resources is the fact that internet access requires significant capital investment in electrification, procuring computers and internet connectivity as well as access to appropriate software. ${ }^{29}$

Despite the factors cited above, the Examination Council of Lesotho (ECOL) has proposed the introduction of the advanced level (A level) to follow the LGCSE as a way, arguably, to reduce the number of years spent at the higher education level and effectively reducing the financial burden on the learners. This also enables eligibility of Lesotho learners for South Africa universities that require a Matriculation Certificate (Matric) that is believed to be at a higher level than the LGCSE. This proposal has been adopted by the Government of Lesotho. ${ }^{30,31}$ Surprisingly, ECOL, the body entrusted with quality assurance of the examinations, seems to be the one driving the curriculum rather than the national strategic development plan through the National Curriculum Development Centre (NCDC) which is a mandated body to develop the national curriculum. In addition, there seems to be an inordinate rush to implement the A level programme in the light of a proposal by the regional countries to develop a regional qualifications framework that will enhance harmonization of secondary school qualifications in the region. ${ }^{32}$

This study is aimed at assessing one aspect of the readiness of the Lesotho's secondary schools for A level chemistry, namely, the status of the laboratory resources for teaching of chemistry. A prior study on the appreciation of the virtual laboratory undertaken using pre-service teachers and final year university students who were engaged in teaching practice in Lesotho revealed that a significant number of students leaving secondary school had not participated in a chemistry experiment. ${ }^{29}$ It is believed that the situation has not improved much since that time, therefore this study is warranted. The other aspects such as the level of qualification of teachers will not form part of this study although studies have demonstrated that a Bachelor's degree does not provide sufficient depth in the teaching subject content to enable teaching the subject at A Level. ${ }^{33}$ Consequently, there is need to consider in-service courses to deepen the content of the in-service teachers as experienced by other countries such as Zimbabwe. ${ }^{34}$

\section{Research Methodology}

\subsection{Profiling the Study Group}

The study was mainly based on the questionnaire distributed to the First Year students enrolled at the National University of Lesotho (NUL) in the three science-based faculties: Faculty of Agriculture, Faculty of Health Science and Faculty of Science and Technology. The questionnaires were distributed to 5/10 different laboratory groups of the first year chemistry course (C109) each with between 50 and 60 students. These groups 
were chosen at random with no background information. The students from the same school were requested to fill the same questionnaire as a group on each day so that they could discuss and come to the agreement about the correct number of experiments they carried out in their school. In total there were 263 students representing 87 schools that took part in this study.

\subsection{Data Collection and Analysis}

The research questions were designed to provide some information regarding the presence and state of physical laboratories, equipment (apparatus and consumables), frequency of carrying out the experiments and the mode of carrying out the experiments (whether the students were allowed to perform the experiments physically or observe as the teacher performed the experiments).

The research questions are listed below. Students were asked to:

- To state the school proprietor and geographical location (urban/rural)

- To state whether the school had laboratory facilities, e.g. a building with or without benches, apparatus and consumables

- To state the number of experiments carried out by the students (whether physically performing them or demonstrations by the teachers) in respective schools

- To establish major reasons for performing (or not) the prescribed number of experiments in the syllabus, if known, or to speculate on the possible reasons if the actual reasons were not known.

The other aspect was to assess the information and communication technology (ICT) penetration taking cognizance of the fact that a previous study recommended the use of e-resources as an alternative to and to complement physical experiments. The uses of these resources, however, depend heavily on the ICT infrastructure.

The data were analysed and presented in charts using Microsoft Excel ${ }^{\circledR}$ software, and no statistics were necessary. The responses that were considered by the researcher to be similar were grouped together for the semi-quantitative analyses. For example, broken taps, no sinks, broken or chipped glassware were all classified as inadequate facilities; old chemicals, unlabelled bottles or reagent containers, expired or discoloured chemicals were classified as old or expired chemicals. Since the study was focused on the schools, the number of responses was reduced from 263 students to 87 schools. The responses from the same school were compared, and where a different response was observed, the response stating a higher number of experiments was taken to ensure a consistent approach to scoring.

\subsection{Ethical Consideration}

Although the researcher works at the same department, there was no student-lecturer relationship that could pressure students into taking part since the researcher was not taking any part in the teaching of this course. The students participated voluntarily in the study without any coercion. Before disseminating questionnaires, the students were briefed by the researcher about the importance of the study and urged those not interested to decline from taking part in the study. The students were further requested to give honest responses to all the questions.

\subsection{Limitations of the Study}

Since this study is based on the students enrolled at NUL only, it might not give the true picture of what is happening on the ground. It only includes the schools whose students have been admitted and registered in the three faculties under the programmes that require First Year level chemistry as a prerequisite. However, since the NUL is the only institution offering natural sciences at a degree level, it is believed that it enrols cream of the crop in the sciences, while the other institutions offer sub-degree programmes in either engineering or science teaching.

\section{Results and Discussions}

\subsection{Profiling the Respondents by District, School Proprietor and Geography}

Lesotho is divided into two main geographical regions, namely, urban and rural. Typically the rural areas are characterized by poor resources, for example lack of electricity and poor roads. As a result, they are reportedly not 'attractive' to the teachers, ${ }^{35}$ although this assumption is not tested in this work. To assess the effect of the geographical region, the results were categorized on the basis of these geographical locations so as to gather some evidence to the extent of the difference in infrastructure due to physical location of the school.

\subsubsection{Distribution of School by District and Geographical Location}

For ease of administration, Lesotho is divided into ten districts each with the two mentioned geographical regions, rural and urban, although in some districts, the urban characterization is restricted to the main central business district, leaving the bulk of the districts to be characterized as having rural status (see Fig. 1). These include Quthing, Qacha's Nek, Mokhotlong and Thaba Tseka. Maseru, which houses the capital city of Lesotho, has four regions that are characterized as urban, namely, Maseru, Roma, Morija and Semonkong, as such it has a higher number of schools with urban status.

As can be seen from Fig. 1 a high population density is located along the western periphery of the country accounting for about $60 \%$ of the total population of the country. ${ }^{36}$

Figure 2 shows the profile of the respondents by the district and the geographic status.

From Fig. 2, it is clear that Maseru has a higher number of students (and schools) who are admitted into the science-based programmes at the National University of Lesotho at just over 25 followed by Leribe at 18 . Only one district, Qacha's Nek did not have a registered student in the sample which consists about $50 \%$ of the first year enrolment of the entire science-based programmes. This is interesting since there are arguments that have been surfacing that perhaps the merit-based admission criteria at the university, where students are treated equally and their performance matched, should be modified to accommodate students from the rural areas. Only one student was identified from the neighbouring Republic of South Africa (denoted as RSA) who happened to have come from the region that was previously 'disadvantaged' during the racial segregation in South Africa.

\subsubsection{School Proprietorship by Geographical Region}

The proprietorship of schools in Lesotho falls into four categories, namely, churches (Christian and Islamic), community, private and government. The responses were therefore analysed and categorized in terms of proprietorship and geographical location. Fig. 3 shows the classification of the respondents by the school's proprietor and geographical location.

As can be seen, the church-based proprietorship dominates the school propriety with 49 Christian schools and one Islamic school out of the 87 schools that were recorded. The government 


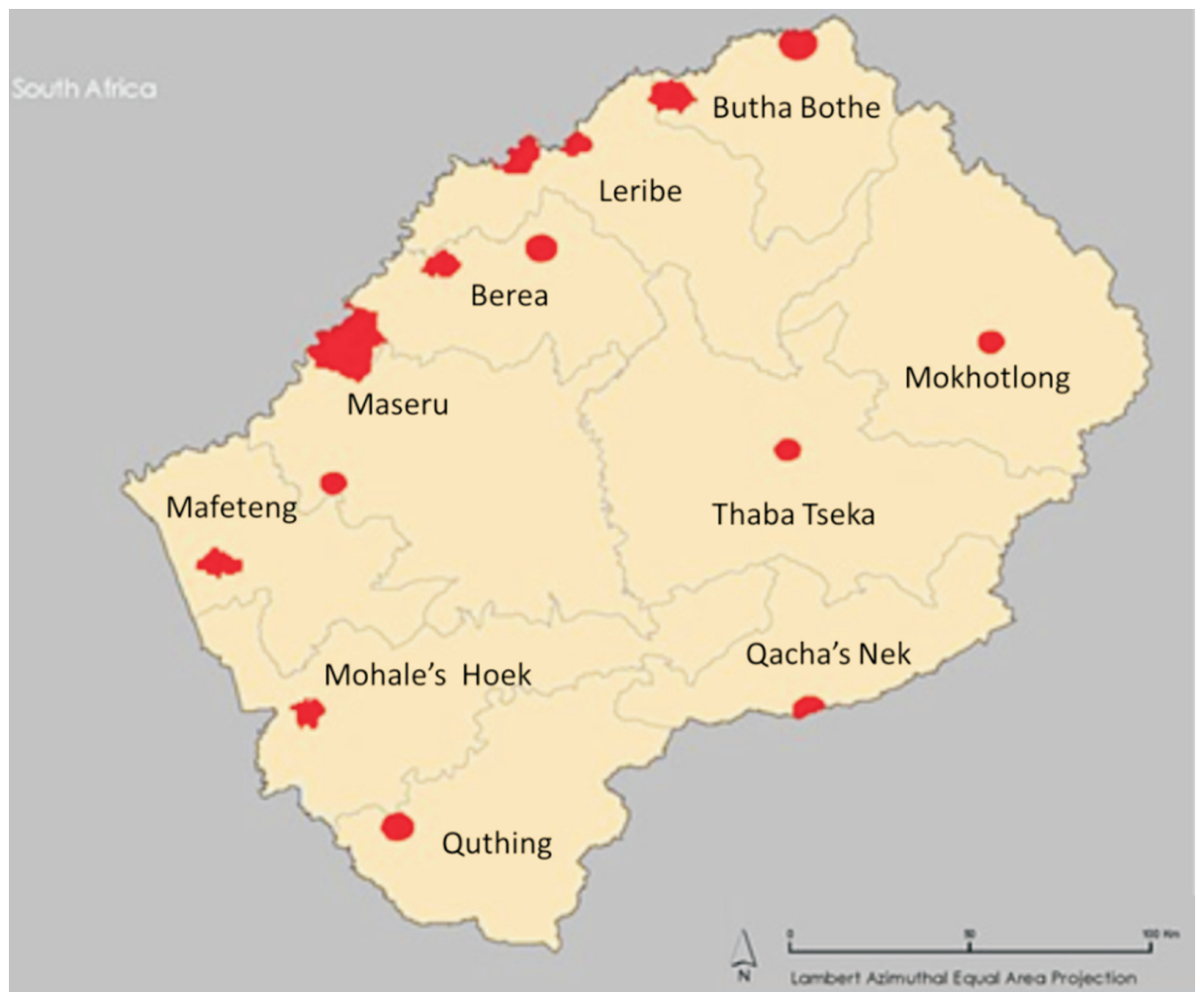

Figure 1 Map of Lesotho showing the urban and peri-urban areas as denoted by the red-shaded area mostly around the periphery of the country (Courtesy of CIESIN, n.d.).

came in second with 17 schools. An analysis of the churches shows that the Roman Catholic Church (RCC) leads the overall propriety with 22 schools, then Lesotho Evangelical Church in Southern Africa (LECSA), the Anglican Church of Lesotho (ACL) with the Methodist Church registering only one school. This is not surprising considering the fact that the first three churches (RCC, LECSA and ACL) are well-established in Lesotho having started operating in Lesotho before the 1900s.

The second interesting aspect demonstrated by Fig. 3 is that most of the schools are in the urban areas. Considering the complete geography of the country, this is unexpected since a substantially high number of schools are in the rural areas. The fact that most of the respondents came from the urban areas could point towards the issue raised in some quarters that perhaps the admission policy needs to consider the two areas on their own merit than the current policy that just assumes that the students have a similar background.

Thirdly, it is interesting to note that all the private schools are located in the urban areas. This is not surprising considering that private schools, by their very nature, are aimed at communities that can afford to pay for their children's school fees so that the proprietors can make some profit, as opposed to the church and government schools that are not for profit but rather are aimed primarily at providing education. The community-owned schools also seem to be located in urban areas. This could possibly be explained in the same manner as the private propriety in that poorer communities would not afford to build their own school hence only those communities in the urban areas

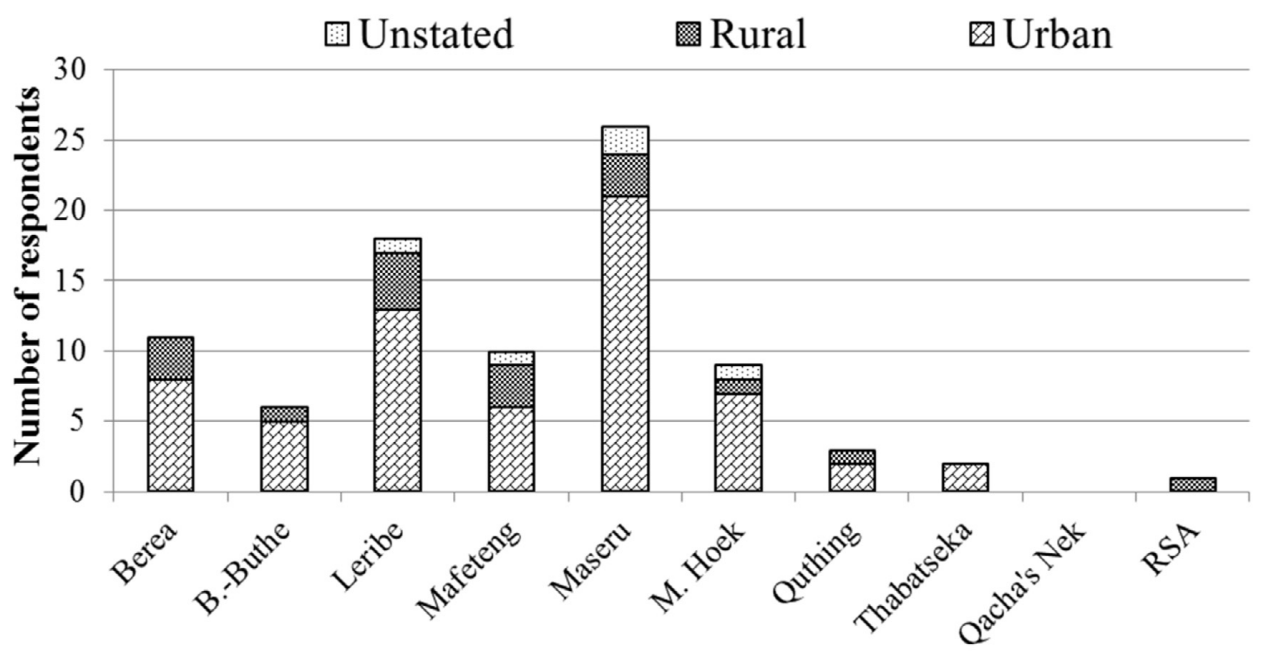

District

Figure 2 Distribution of schools whose students took part in the study by district and geographical location. The frequency of responses in the figure indicates the number of respondents (schools). 


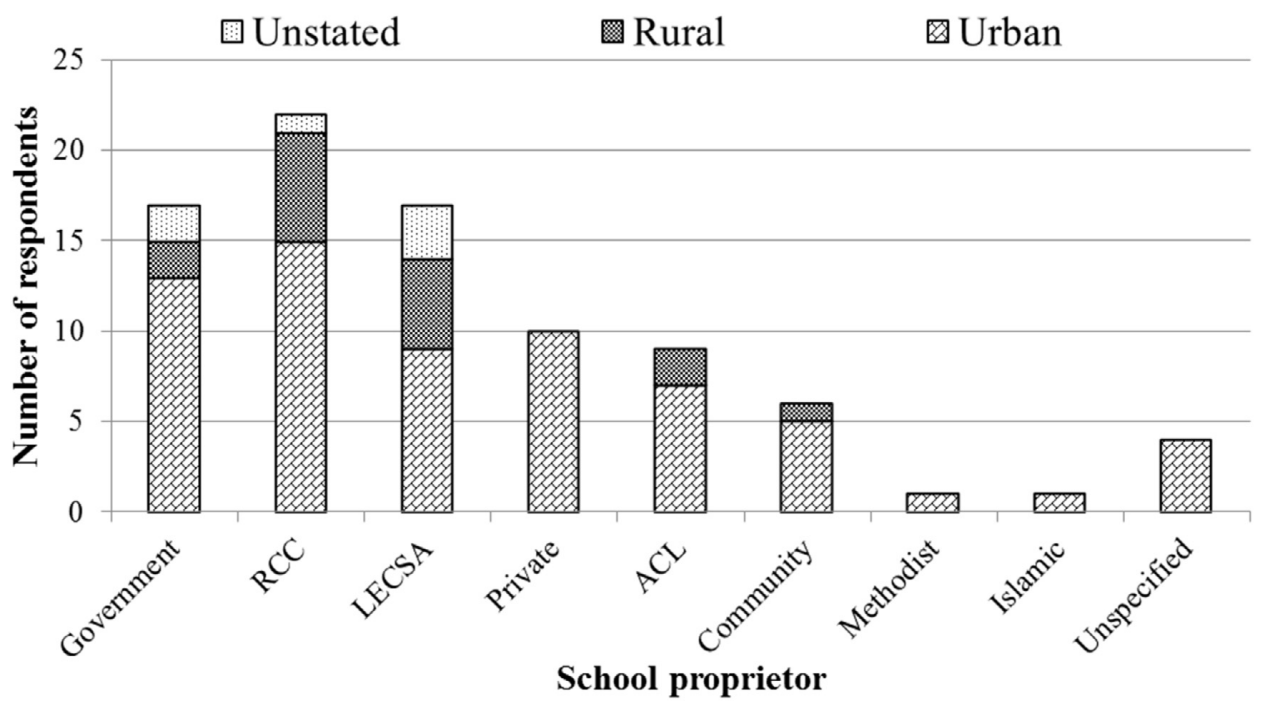

Figure 3 Distribution of schools whose students participated in the study by proprietor and geographical location. The acronyms RCC, LECSA and ACL denote Roman Catholic Church, Lesotho Evangelical Church in Southern Africa and Anglican Church of Lesotho, respectively.

with resources can afford to raise resources to build community schools.

\subsection{Assessment of the Availability and the Use of Laboratory Facilities in Schools}

The main purpose of the study was to establish the resourcing of the laboratories for carrying out the experiments. Firstly the determination of whether the schools have laboratory facilities, if any experiments were performed, reasons for not doing any (fewer than required) experiments, were asked and the responses are presented and discussed in the next few sections.

\subsubsection{Assessment of the Physical Presence of the Laboratory Facilities} by School Proprietor and Geographical Location

To assess this, the respondents were asked to respond to the question of whether their schools had physical laboratories, whether functional or not. Fig. 4 shows the distribution of schools by geographical location and general proprietor that had physical laboratories.

As can be seen, the majority of schools have the physical laboratories. Only a few schools (8/87) did not have laboratories. Among these schools four were owned by the churches, three by government while one was a community-school. It was reported that the government schools concerned were newly built hence the laboratories were not yet equipped or not designated appro- priately, thus the students did not know whether or not some rooms would be used as laboratories. As for the rest, there were no physical buildings and/or rooms designated as laboratories.

\subsubsection{Number of Experiments Performed per School Classified by Geographical Location}

Following the determination that the majority of the schools sampled did have at minimum a classroom designated as a laboratory, the next issue was how many experiments were performed on average over the two years of LGCSE. Fig. 5 shows the number of experiments performed per year by the number of schools and their respective geographical region.

The results show that most of the schools performed only a handful of experiments. This is consistent with the studies reported where a similar determination was made earlier. ${ }^{29}$ Only a few schools performed more than ten experiments of about 20 prescribed set of experiments from the syllabus. Interestingly the schools that seem to perform more experiments are in the urban areas where the range of the number of experiments covers both extremes (from 0 to 20 ) while those in the rural areas peaked at 10 experiments (one school) and four recording no experiments at all.

Figure 6 categorizes the responses in Fig. 5 by proprietorship of the school. The importance of this is to assess the level of resources in government schools which were expected to be

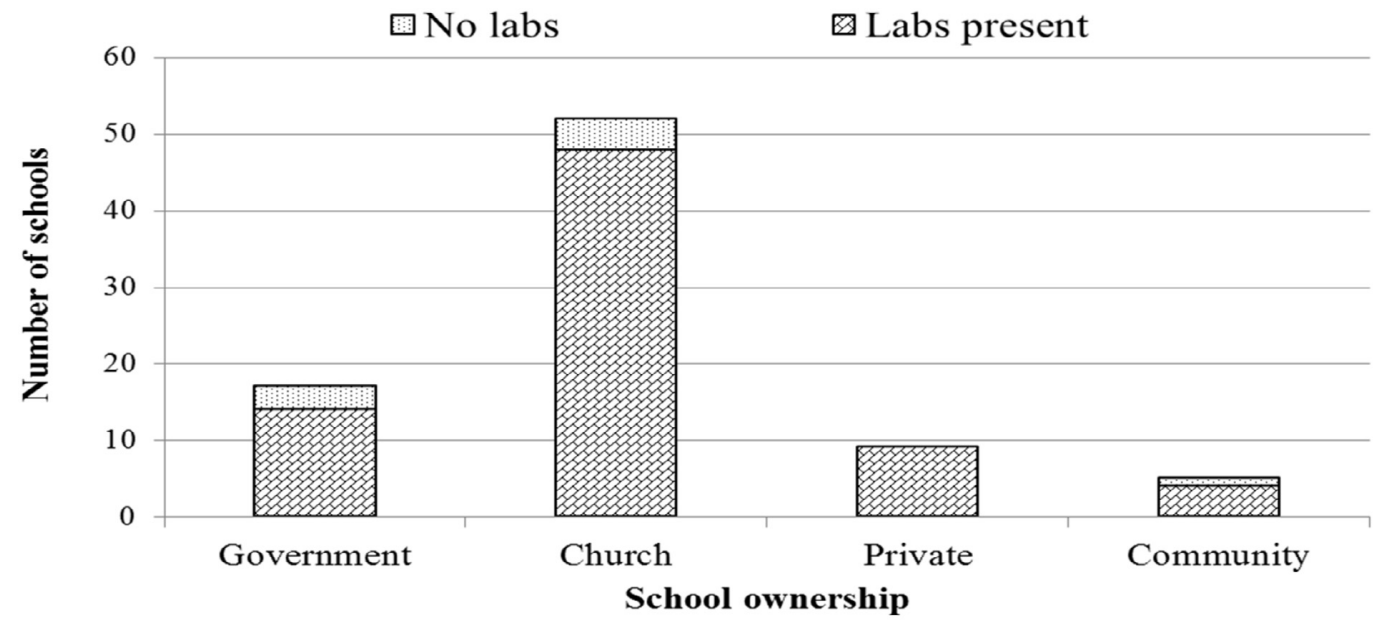

Figure 4 Assessment of the availability of physical laboratories in schools by proprietor. 


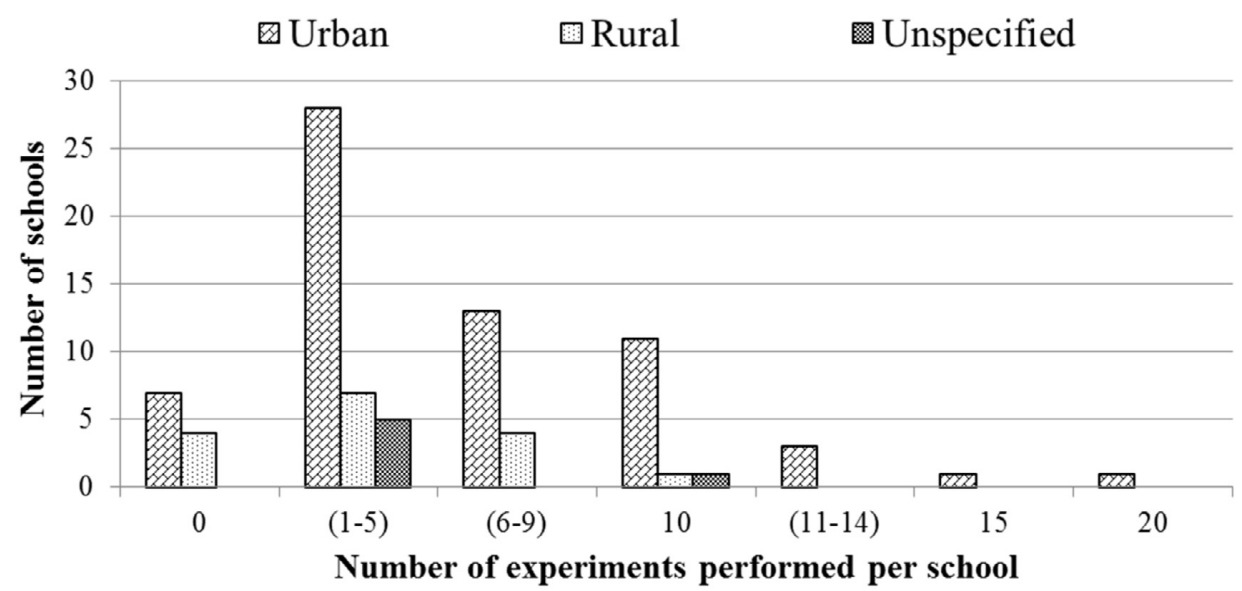

Figure 5 Number of experiments performed per school by geographical area.

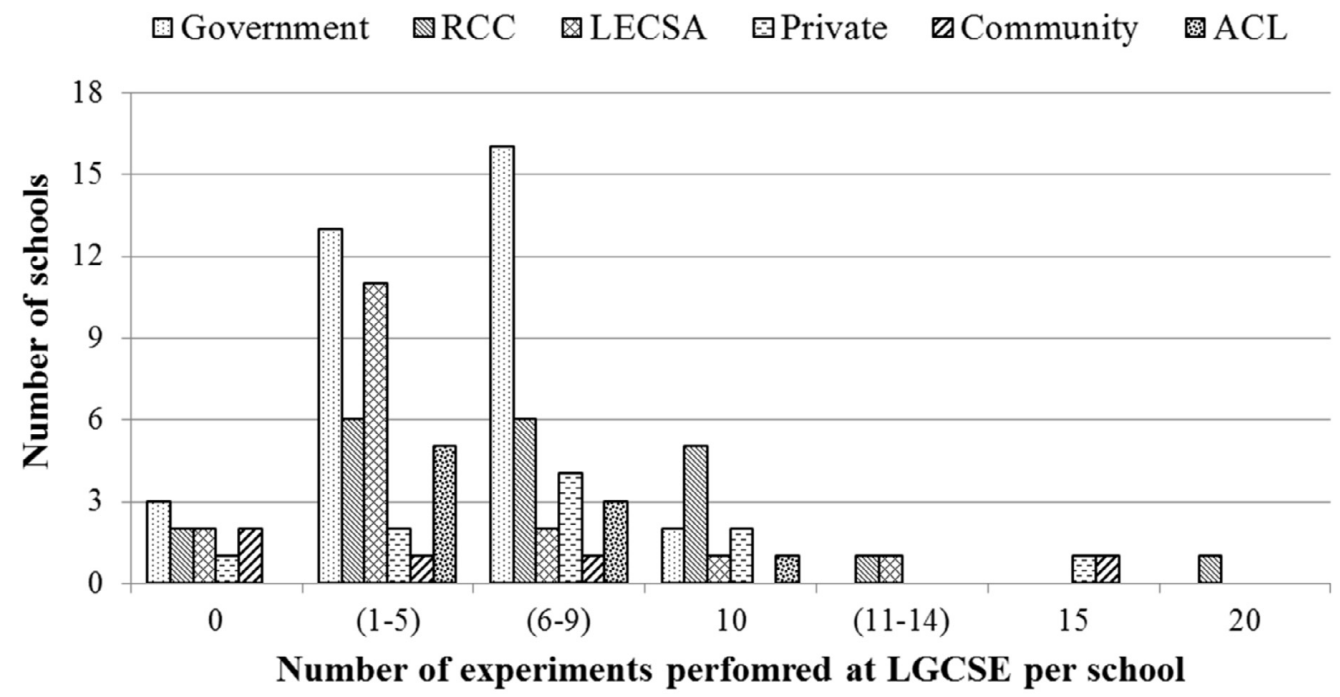

Figure 6 Number of experiments performed categorized by the proprietor of the schools.

better equipped and well managed since they are expectedly under the watchful eye of the ministry.

What is interesting about these results is that no government school featured in the schools that performed more than ten (11-20) experiments; not even those schools identified by Examination Council of Lesotho to pioneer the A level syllabus. Of the five best performing schools, those with eleven to twenty experiments, four are owned by the churches and one a community school, with 'Mabathoana RCC topping the list with 20 experiments. Students from 'Mabathoana reported that experiments were scheduled every three weeks. The best performing schools under the proprietorship of government recorded having carried out ten experiments; these schools were in the urban areas (regional categorization not shown in the figure). The majority of the schools whose students took part in the research carried out between seven and a disappointing zero number of experiments. What can be concluded in this section is that the non-government schools seem to be doing relatively well despite the reported poor government support.

\subsubsection{Reasons for Not Doing more Experiments}

Given the low number of experiments which were reportedly performed; the reasons for the number of experiments they performed were analysed. As stated in the methods section, the responses that were deemed similar were grouped to arrive at a few reasons that were then populated as in Table 1.
From the reasons mentioned by the students, it is clear that inadequate facilities (33\%) and inadequate chemicals (31\%) dominate the reasons. The facilities in this context referred to the actual physical laboratory structure and apparatus. It is interesting to note that the combined $64 \%$ for inadequate resources closely matches the $66 \%$ reported in the earlier study. ${ }^{29}$ Most of the students reported that the laboratories lacked adequate basic infrastructure such as standard laboratory benchtops. They had chapped floors, broken (or no) taps, dysfunctional or no fumehoods and even broken or chipped glassware for carrying out the experiments. The chemicals mentioned in Table 1 referred to the actual chemicals that are used in the experiments. The inadequacy in the case of chemicals referred to the physical absence of chemicals and the expired or contaminated chemicals that were no longer usable.

Some students $(2 \%)$ reported that their teachers were lazy. These students reported that their teacher kept on postponing the experiments to the subsequent week indefinitely with no clear reasons until the year was over.

The reasons stated for not performing the prescribed number of experiments are in good agreement with those observed and reported in an earlier study. ${ }^{29}$ Clearly infrastructure plays a big role in this case. The other important aspect is the enabling policy - science experiments are not scheduled on the timetable (cited by some $7 \%$ of the respondents) which leaves only individual commitment and motivation by the teachers to perform 
Table 1 Reasons cited for not doing the reported number of experiments performed by each school.

\begin{tabular}{lc}
\hline Possible reasons cited for not doing the reported experiments & Response (\%) \\
\hline Inadequate facilities (laboratory, broken or no apparatus) & 33 \\
Inadequate chemicals (lack of chemicals) & 31 \\
Poor safety (no fumehoods) & 7 \\
Experiments not scheduled in the timetable & 4 \\
Poor lab state (chapped floors, broken gas pipes) & 3 \\
Overcrowding (high student to teacher ratio) & 3 \\
No physical laboratory buildings (includes benches) & 3 \\
Too old ('expired') chemicals (some without proper labelling) & 2 \\
Adequate experiments (students felt they did adequate experiments) & 1 \\
Lazy teachers (teachers kept postponing the experiments indefinitely) & 1 \\
Newly built school (with no laboratory building assigned yet) & \\
Reasons unknown to students & \\
\hline
\end{tabular}

the experiments. This sometimes comes at the expense of the other equally important extra-curricular activities such as sports and music that are regarded as important for sharper minds while also assisting students to identify their extra-curricular talents besides education.

\subsubsection{Assessing the Mode of Performing the Experiments}

The mode of performing the experiment is very important to accommodate the kinaesthetic students i.e. those that learn better following the hands-on experimentation rather than making observations. ${ }^{37}$ The next task was therefore to analyse the responses on how the experiments were performed. Fig. 7 shows the responses over the two different modes, namely, students carrying out the experiment or a demonstration by the teacher.

As can be seen from Fig. 7, the preferred mode for experiments is demonstration by the teacher $(43 \%)$ with $29 \%$ of the students doing the experiment by themselves. $27 \%$ of students reported employing two modes where the teacher would perform a demonstration after which the students were asked to perform the experiments themselves. Only one school was reported to sometimes selecting a few (possibly the best) students to help with the demonstrations to other students. While this could help to motivate the students who physically do the experiments, and to some extent those observing, this could also negatively affect the observing students if they are never chosen, as they could feel less important consequently losing interest in the experiments and the subject as a whole. Therefore, it is recommended that when teachers employ this mode, they should be mindful to be inclusive lest they become too biased.

\subsection{Assessment of the Information and Communication Technology Penetration in Schools}

ICT is one of the most versatile and contemporary resource used in teaching and learning. It was thus prudent to assess the accessibility of ICT infrastructure at schools. Responses regarding the questions on availability of a computer, access to the internet, and whether the internet access was available to students and to some extent even teachers were analysed. Fig. 8 shows the penetration of ICT in the schools whose students participated in the study.

As can be seen from Fig. 8, just over $10 \%$ of the schools in the rural areas reported the presence of a computer in the school, of that $10 \%, 7 \%$ reported that there was internet connectivity at the school. This is contrary to the urban areas where about $60 \%$ of the schools had a computer and just fewer than $30 \%$ had internet connectivity. Interestingly, only three schools reportedly allowed their students access to computers and the internet for their school work. Some students reported that the computers in their school were only accessible to the principal and the secretary, not even the teachers could access them.

\section{Conclusions and Recommendations}

The primary role of this study was to assess the resource readiness of the Lesotho schools that have produced students eligible for admission to the science-based programmes at the National

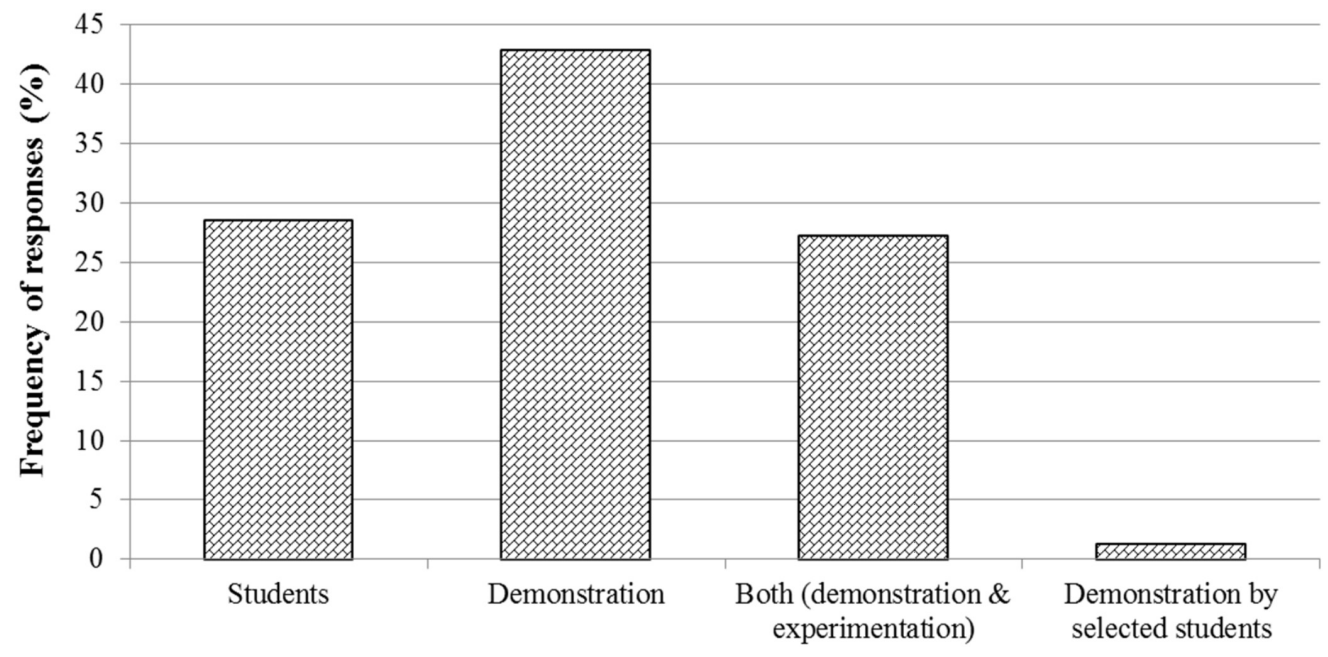

Mode of experiment

Figure 7 The mode of carrying out the experiment in different schools. 


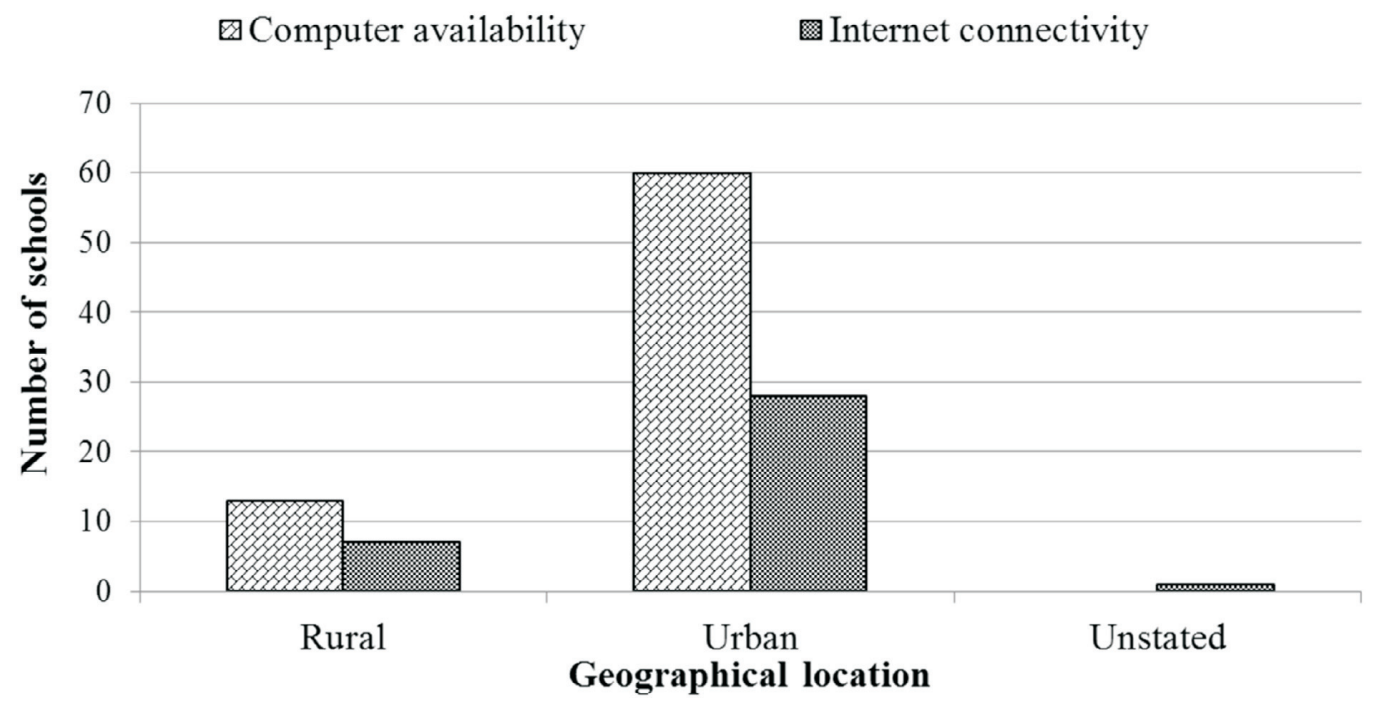

Figure 8 Assessment of the information and communication technology (ICT) in the schools.

University of Lesotho. The findings for the main objective of the study are summarized below. Primarily, one can conclude that the schools in Lesotho are not ready for the A level teaching of chemistry, possibly other sciences as well. The level of laboratory facilities are still far too poor to adequately cater for A level chemistry which ideally should be pitched at the first year level of the university chemistry education. There is a fear that should the A level implementation go ahead as planned, it could simply lead to a high failure rate at the university level since the students would be enrolled at the second year level at which they will be expected to have acquired sufficient skills to handle the experiments by themselves.

The second lesson learned is that, contrary to what was expected, the church-owned schools seem to be equally equipped, albeit poorly, compared to the government-owned counterparts, with the former doing more experiments than the latter. This finding was not expected given that the church schools are blamed for lack of transparency in hiring teachers at strategic positions such as principals, deputies and even heads of departments. The private schools seem to be the worst performing in this regard. This confirms the fact the sciencebased programmes are regarded as the most expensive, hence private schools, being profit-driven, would certainly shy away from undertaking certain activities that are deemed to negatively affect their profits.

Thirdly, most of the 'best performing' school with regard to the national examinations results (JC and COSC), do not feature in the schools that attempt to perform the experiments, and hence compromise this important aspect of chemistry learning. ${ }^{25,28}$ This raises the question of whether these schools teach their pupils according to the objective of the curriculum or to prepare the students for the examinations. Already there are untested claims that most of the students from these 'top performing schools' do not perform well at the first year of the university education. If this is indeed the case, then it could be explained in part by this study.

Fourthly, most of the schools perform the experiments by way of demonstration. This was attributed to the number of students per class, while it could also be due to the time required for the experiments. At the university, an experiment session is scheduled for three hours; it is therefore understandable that if the experiments are not provided for in the normal teaching timetable where it would be inconceivable to expect the teachers to find the three hours for effective performance of the experiment to allow the students to perform such experiments physically. Schools such as 'Mabathoana High School, should be commended for the efforts as well as being consulted and used as a model school in this regard. It would be interesting to establish how the students from this school perform at the university level compared to those coming from other schools that have not participated in any form of experimentation.

Based on this study the following recommendations can be made, firstly, the status quo of LGCSE should be retained until it can be evaluated where it is failing the country. Both ECOL and NCDC should be engaged robustly through wider stakeholder participation to establish the benefit and necessity of introducing A level in place of the recently introduced LGCSE whose deficiencies have not been documented. Secondly, if the Government of Lesotho cannot be dissuaded from going ahead with the A level, a more inclusive and deeper research project is required concerning 1 ) the resources available as a considerable financial investment would be required to establish and equip the laboratories); as well as 2) the academic qualification of the teachers as it has been suggested that a Bachelor's degree with Education offers insufficient depth to enable teaching the subject at A Level. Alternatively, the Government should consider establishing a few intermediary colleges to offer A level education, especially in the science-based programmes using some of the schools that already have boarding facilities so that students from every part of the country could have access to them. Should this curriculum be introduced under the current circumstances, the country could be headed for an academic disaster, with no prospect of any success, and hence Lesotho shall never benefit from engaging science and technology in the economic development of the country.

\section{References}

1 Curtin University, Enabling Course for Science, Engineering and Health, retrieved on 5 January 2016 from http://courses.curtin.edu. $\mathrm{au} /$ course_overview/undergraduate/science-engineering-enabling

2 G.A. Tularam, Mathematics in finance and economics: importance of teaching higher order mathematical thinking skills in finance, e-J. Bus. Edu. Scholar. Teach., 2013, 7(1), 43-73.

3 J. Mullich, Rising to the challenge - America's math and science curriculum is key to future competitiveness, The Wall Street Journal, 2009. Retrieved on 6 January 2016 from http://online.wsj.com/ad/article/mathscience-rising

4 L. Roberts, Learn maths to boost the economy, scientist advises, The Telegraph, 2010. Retrieved on 6 January 2016 from http://www.tele- 
graph.co.uk/education/educationnews/8142249/Learn-maths-toboost-the-economy-scientist-advises.html

5 E. Smyth and C Hannan, School effects and subject choice: the uptake of scientific subjects in Ireland, Sch. Eff. Sch. Improv., 2006, 17(3), 303-327.

6 G. Steiner-Khamsi and P. Lefoka, Recruitment into Teaching, Teacher Development and Teacher Retention in Lesotho, UNICEF ESARO \& UNICEF LESOTHO, Maseru, Lesotho, 2011.

7 A. Irwin and B. Wynne, Misunderstanding science?: The public reconstruction of science and technology. Cambridge University Press. UK, 1996.

8 A. Pouris and A. Pouris, The state of science and technology in Africa (2000-2004): A scientometric assessment, Scientometrics, 2009, 79(2). 297-309.

9 World Bank, Country Reports - Lesotho, 2015. Retrieved on 6 January 2016 from http://www.worldbank.org/en/country/lesotho/overview

10 Central Bank of Lesotho, Labour market developments in Lesotho, Economic Review. 113, 2009. Retrieved on 13 June 2014 from www. centralbank.org.ls/publications

11 H.M. King Letsie III, Vice Chancellor's Inauguration Speech, National University of Lesotho, Roma, Lesotho, 2015.

12 M.N. Ntho, Lesotho Effective Delivery of Public Education Services, A review by AfriMAP and the Open Society Initiative for Southern Africa, Open Society Foundations, Johannesburg, South Africa, 2013.

13 P. Lefoka, Out of school missing boys - a study from Lesotho, Commonwealth Education Partnerships, 2007. Retrieved on 12 May 2014 from http://www.cedol.org/wp-content/uploads/2012/02/212-2152007.pdf

14 W.G. Nkhoma, Role of education sector in providing care and support to OVC in Lesotho and Swaziland, Open Society Initiative for Southern Africa (OSISA), 2013. Retrieved on 6 January 2016 from http://www.osisa.org/open-learning/lesotho/lesotho-education- system

15 United Nations, Common Assessment of Lesotho - The United Nations System in Lesotho, A United Nations Country Report, Washington DC, USA, 2004.

16 African Economic Outlook (AEO), Lesotho 2014. Retrieved on 21 March 2015 from http://www.africaneconomicoutlook.org/en/country-notes/lesotho

17 J. Hamer and R. Murphy, CHE study on introduction of advanced subsidiary or advanced levels: implications for higher education institutions and readiness of secondary school system to offer AS or A-levels in Lesotho, Council on Higher Education, Maseru, Lesotho, 2015.

18 J. Urwick, P. Mapuru and M. Nkhoboti, Teacher motivation and incentives in Lesotho College of Education, Maseru, Lesotho. 2005 Retrieved on 24 July 2017 from http://www.eldis.org/vfile/upload/1/ document/0709/Teacher_motivation_Lesotho.pdf

19 C. Bitso, Enviromental education and networking in Mafeteng primary schools: a participatory approach, TOJDE, 2006, 7(1), 30-40.

20 UNDP Lesotho, Parliamentarians Investigate School Fees, Press Release, 16 July 2013. Retrieved on 27 January 2016 from http://www. ls.undp.org/content/lesotho/en/home/presscenter/articles/2013/07/ 16/parliamentarians-visit-secondary-and-high-schools-to-investigat e-school-fees.html
21 V.S. Mncube and S. Makhasane, The dynamics and intricacy of budgeting in secondary schools in Lesotho: case studies of three high schools, Afr. Educ. Rev., 2013, 10(2), 347-363.

$22 \mathrm{~S}$. William, Effects of integrated video media on student achievement and attitudes in high school chemistry. J. Res. Sci. Teach., 1997, 34(6), 617-631.

23 M.C. Lebata and A.V. Mudau, Exploring factors affecting performance in Biology 5090 at selected high schools in lesotho, Medit. J. Soc. Sci., 2014, 5(8), 271-278.

$24 \mathrm{M}$. Lekhetho, Stakeholder perceptions about factors that cause poor student performance in Cambridge Overseas School Certificate (COSC) examinations in Lesotho, Int. J. Educ. Sci., 2013, 5(4), 385-395.

25 D.H. Beach and M.H. Stone, Survival of the high school chemistry lab, J. Chem. Educ., 1988, 65(7), 619-620.

26 R.D. Jansen-van Vuuren, M S. Buchanan and R.H. McKenzie, Connecting resources for tertiary chemical education with scientists and students in developing countries, J. Chem. Educ., 2013, 90,1325-1332.

27 L.H. Laroche, G. Wulfsberg and B. Young, Discovery videos: a safe, tested, time-efficient way to incorporate discovery-laboratory experiments into the classroom, J. Chem. Educ., 2003, 80(8), 962-966.

28 A.Velázquez-Marcano,V.M. Williamson, G. Ashkenazi,R. Tasker and K.C. Williamson, Use of video demonstrations and particulate animation in general chemistry, J. Sci. Educ. Technol., 2004,13(3), 315-323.

29 M.J. George and M. Kolobe, Exploration of the potential of using a virtual laboratory for chemistry teaching at secondary school level in Lesotho, S. Afr. J. Chem., 2014, 67, 113-117.

30 L.V. Ketso, Budget Speech to Parliament for the 2013/2014 Fiscal Year, Ministry of Finance, Maseru, Lesotho, 22 February 2013.

31 National Strategic Development Plan, 2012/13 - 2016/17, Government of Lesotho, 2014, p. 114.

32 Southern African Regional Universities Association, Building regional higher education capacity through academic mobility, Leadership Dialogue Series 3(1), 2011. Retrieved on 7 April 2015 from http://www.sarua.org/files/publications/SARUA\%20leadership $\% 20$ Dialogue \% 20Series/Leadership \% 20Dialogue\% 20series\%20Vol\% $203 \% 20$ No $\% 201$.pdf

33 K. Chavunduka, Improving Science Education in Zimbabwe: the Role of Resource Teachers in Professional Development, $\mathrm{PhD}$ thesis, University of Twente, Enschede, Netherlands, 2005.

34 Y.N. Gwekwerere, E. Mushayikwa and V. Manokore, Empowering teachers to become change agents through the science education in-service teacher training project in Zimbabwe, Comp. Int. Educ., 2013, 42 (2), 1-16.

35 J. Jha, Boys' Lower Participation in Schools in Lesotho, Access to Education - ID 21 Education Highlights 5. Retrieved on 6 January 2016 from http://r4d.dfid.gov.uk/PDF/Outputs/IDS/education5-accessto education.pdf

36 L. Maqalika-Lerotholi, Tutition fees in Primary and Secondary Education in Lesotho: the Levels and Implications for Access, Equity and Efficiency, International Institute of Educational Planning, UNESCO, Paris, France, 2001. Retrieved on 27 January 2016 from http://unesdoc.unesco.org/images/0012/001235/123535e.pdf

37 R. Dunn and K. Dunn, Teaching Students through their Individual Learning Styles. Reston, Victoria, Australia, 1978. 